\title{
A Critical Band Filter in Touch
}

\author{
James C. Makous, Robert M. Friedman, and Charles J. Vierck, Jr. \\ Department of Neuroscience, University of Florida, Gainesville, Florida 32610-0244
}

\begin{abstract}
Separate mechanoreceptor systems in humans were isolated by varying the spectra of vibrotactile stimuli. First, the function relating threshold to frequency of a sinusoid was obtained on the fingertip for each of four subjects, and it was found to comprise two limbs: a Pacinian and a nonPacinian limb. The peak sensitivity within the Pacinian limb (mediated by Pacinian corpuscles) was around $250 \mathrm{~Hz}$ and spanned the region from 65 to $400 \mathrm{~Hz}$. The non-Pacinian limb showed no detectable change in sensitivity in the region between 10 and $65 \mathrm{~Hz}$. These two limbs were then treated as psychophysical channels in experiments in which narrow band noise and individual sinusoids were used to excite one or both channels. In the second and third experiments, the noise stimuli varied in bandwidth from 8 to $70 \mathrm{~Hz}$ and varied in center frequency from 25 to $218 \mathrm{~Hz}$. Masking functions were obtained for ON-frequency conditions (the sinusoidal test and noise masker occupied the same frequency region) and for OFF-frequency conditions (the test and masker occupied different frequency regions). The ON-frequency experiments were used to estimate the signal-to-noise ratio $(\mathrm{S} / \mathrm{N})$ of the Pacinian channel at threshold. The OFF-frequency masking experiments were used to infer the shape of the Pacinian channel at frequencies below $65 \mathrm{~Hz}$, where thresholds for Pacinian activation were above detection threshold. The results of these three experiments predicted the findings of a fourth masking experiment with a parameter free model that treated the Pacinian channel as a filter that integrates stimulus power. The results show that the Pacinian channel is analogous to a critical band in the auditory system.
\end{abstract}

[Key words: touch, vibrotaction, critical bands, somatosensory, skin, psychophysics]

The nervous system must be able to extract specific information from complex (noisy) stimuli. One property that the nervous system has developed to deal with this problem is to separate neural elements that respond to different dimensions of stimuli into independent, parallel sensory pathways (Müller, 1838; cit. Dennis, 1948). Without parallel channels, the system would be limited by the principle of univariance (Rushton, 1972). That is, the stimulus may vary in intensity or frequency, but the receptor potential can only vary along a unitary dimension: amplitude.

\footnotetext{
Received June 10, 1994; revised Oct. 17, 1994; accepted Oct. 20, 1994.

We acknowledge the technical support of James Murphy, Laura Kasper, and Anita Puente. We also thank David Green and Walter Makous for many valuable discussions and two anonymous reviewers for helpful comments on the manuscript. This research was supported by Grant NS 07261 .

Correspondence should be addressed to James C. Makuus, Institute for Sentsory Research, Merrill Lane, Syracuse University, Syracuse, NY 13244-5290. Copyright (c) 1995 Society for Neuroscience 0270-6474/95/152808-11\$05.00/0
}

Thus, the presence of multiple pathways should be evident as different psychophysical channels that are relatively insensitive to interactions between stimuli that activate the different neural pathways.

The idea that sensory systems analyze information in independent filters or channels has proved useful in modeling numerous visual processes. For example, color and luminance have been modeled by two color-opponent channels and an achromatic channel (DeValois and DeValois, 1975; Hurvich, 1981; Lennie and D'Zmura, 1988). Spatial and temporal visual processes have also been modeled by a bank of frequency selective filters (Campbell and Robson, 1968; Blakemore and Campbell, 1969; Graham and Nachmias, 1971; Watson and Robson, 1981; Mandler and Makous, 1984; Shapley and I ennie, 1985; Graham, 1989; Waugh and Hess, 1994). All of these channels must then ultimately combine to yield a unified percept.

There is also ample evidence that the auditory system contains parallel psychophysical channels that filter and integrate the power of stimuli within "critical bands" (Fletcher, 1940; Greenwood, 1961; Scharf, 1970; Patterson, 1974, 1976). Although the energy integrator model has recently come into question (Henning et al., 1975; Green and Forrest, 1986; Richards, 1992), its utility in modeling the results of numerous experiments cannot be disputed.

In addition, the idea of channels was postulated for the somatosensory system by Verrillo (1963) and later by Mountcastle and colleagues (Talbot et al., 1968) in the context of flutter vibration. Since that time, an extensive series of studies culminated in the four channel model for touch proposed by Bolanowski and others (Verrillo, 1963; Verrillo and Gescheider, 1977; Gescheider et al., 1983; Gescheider et al., 1985; Bolanowski et al., 1988). Although the existence of psychophysical channels has been demonstrated for the somatosensory system, only two previous studies have addressed whether these channels have properties similar to critical bands in the auditory system. Verrillo and Gescheider (1975), as well as Marks (1979), found cvidence for cnergy summation within the Pacinian channel and loudness summation across channels, consistent with the critical band model. The usefulness of this model arises from the fact that the filter is assumed to be a linear integrator of energy. If this is indeed the case, then the output of the channel can be predicted from the power spectrum of any stimulus. This then allows one to model more complex stimuli, and one can more easily evaluate possible interactions among different channels.

The current experiments were undertaken to determine if the psychophysical channels for touch have properties similar to critical bands. We report here that the somatosensory channel mediated by the Pacinian corpuscle integrates the stimulus power activating the channel and behaves like a classical critical band in the auditory system. 

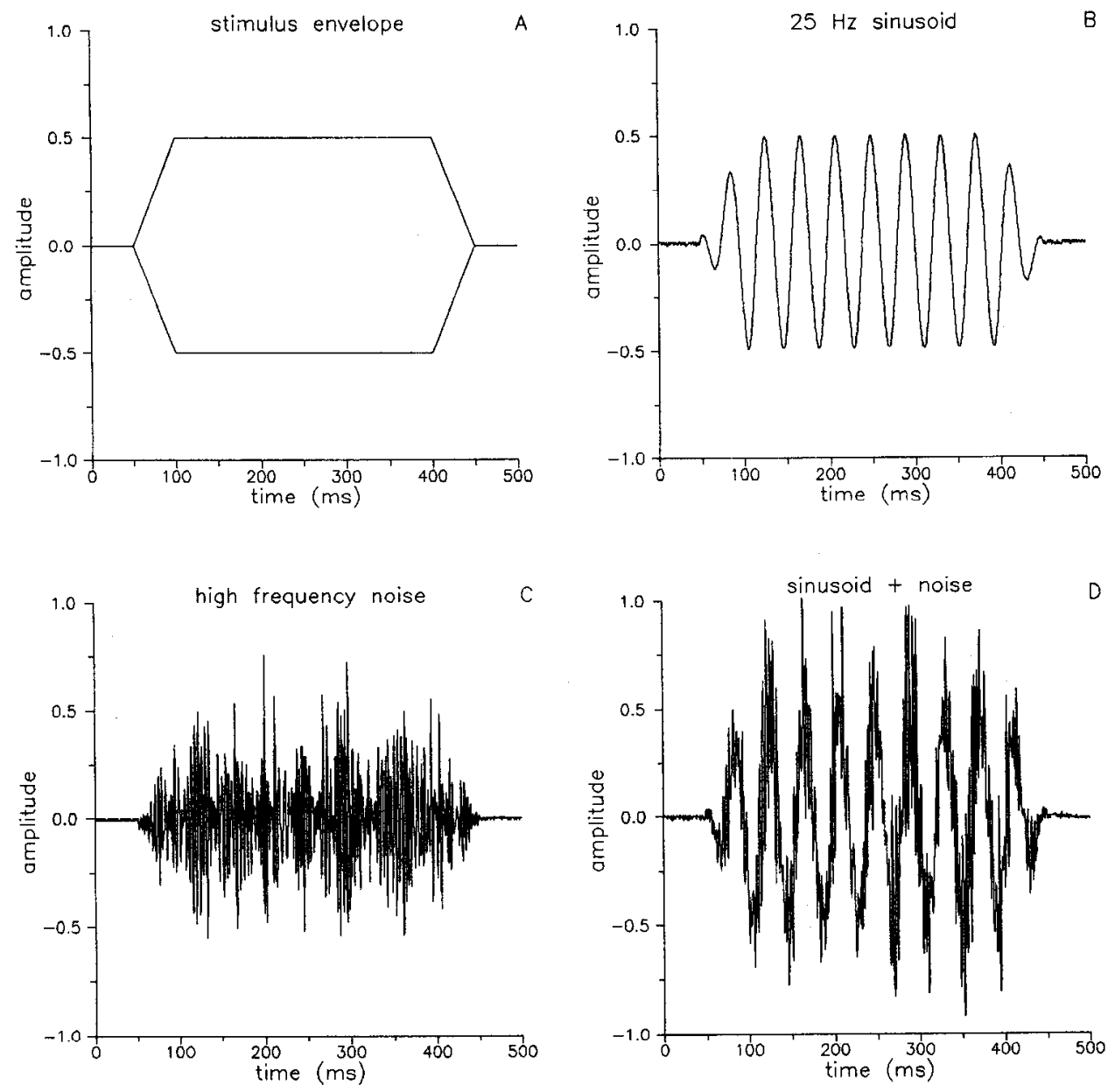

Figure 1. Time course of representative stimuli. The ordinate scale is arbitrary amplitude. $A$, 'The stimulus envelope. The total duration was 400 msec, including a $50 \mathrm{msec}$ rise-decay time. $B$, A $25 \mathrm{~Hz}$ sinusoidal displacement of the skin. Positive values represent compressions of the skin, whereas negative values represent rarefactions of the skin. $C$, High frequency $(218 \mathrm{~Hz}$ center frequency) band limited Gaussian noise. $D$, Sum of the high frequency noise and the $25 \mathrm{~Hz}$ sinusuid. This is an example of one of the masking conditions.

\section{Materials and Methods}

Subjects. Experiments were conducted with three male right-handed subjects and one female left-handed subject, aged 22, 27, 30, and 55 years. All subjects were recruited from the laboratory staff, including the authors, and were trained 5-10 hr on the general task before beginning data collection. In addition, each subject had a minimum of $1 \mathrm{hr}$ of training on each of the individual tasks.

Apparatus and stimuli. Vibrotactile stimuli were delivered through a vibrator (Ling Dynamic Systems, model 102, Yalesville, CT) mounted on an adjustable platform under a table. A small circular contactor (4 mm diameter; $0.13 \mathrm{~cm}^{2}$ ) attached to the vibrator was passed through a $6 \mathrm{~mm}$ diameter hole in the table. The $1 \mathrm{~mm}$ annular gap between the contactor and the table limited the spread of vibrations across the skin (Verrillo, 1962; Gescheider et al., 1978). The contactor was indented into the skin $0.5 \mathrm{~mm}$ beyond its initial contact to prevent decoupling of the contactor from the skin during stimulation. Stimulus amplitude was determined through the calibrated output of a linear variable differential transducer (LVDT, Lucas Schaevitz, Pennsauken, NJ) mounted over the moving element between the vibrator and the contactor.

Stimuli consisted of gated bursts of sinusoids and/or noise. All stimuli had a linear rise-decay time of $50 \mathrm{msec}$ and were a total of $400 \mathrm{msec}$ long. The trapezoidal stimulus envelope is represented in Figure 1A. In instances in which both sinusoidal (Fig. $1 B$ ) and noise stimuli (Fig. $1 C$ ) were presented simultaneously, they were added together before they were gated (Fig. $1 D$ ). Sinusoidal stimuli ranged in frequency from 10 $\mathrm{Hz}$ to $400 \mathrm{~Hz}$ and were generated by passing a sine wave from a signal generator (Leader Instruments Corp., Hauppauge, NY) through a custom made electronic switch. Noise stimuli were shaped by passing the output of a Gaussian white noise source through a variable band-pass filter (12 dB/octave roll-off; Avens Signal Equipment Corp., Elmhurst, $\mathrm{NY}$ ) and then through the electronic switch.

Stimulus amplitudes were measured stroboscopically under a microscope and were related to the output of the LVDT. All spectral measurements were obtained with the finger on the contactor. Except where noted, stimuli are plotted in decibels [dB re: $1 \mu \mathrm{m}$ root-mean-squared (rms) amplitude]. For example,

$$
\log \text { threshold }(\mathrm{dB})=20 \cdot \log \left(\frac{\text { threshold amplitude }}{1 \mu \mathrm{m}}\right) .
$$

Masker levels were expressed in $\mathrm{dB}$ above threshold (i.e., sensation level, SL). Each masker threshold was determined by three threshold determinations on each of three separate days.

The amplitude spectra of the stimuli used in the masking experiments are shown in Figure 2. The spectra of the $25 \mathrm{~Hz}$ and the $200 \mathrm{~Hz}$ sinusoids are shown in Figure $2 A$. The spectra of the noise stimuli are shown in Figure $2 B$. The five low frequency noise stimuli were all centered between 25 and $55 \mathrm{~Hz}$, and varied in bandwidth (defined at the $-3 \mathrm{~dB}$ points) between 8 and $25 \mathrm{~Hz}$. The spectra are displaced vertically for clarity, with bandwidth increasing from the bottom to the top of Figure $2 B$. The single high frequency noise stimulus was centered at $218 \mathrm{~Hz}$ and had a BW of about $70 \mathrm{~Hz}$.

Procedure. Each subject was seated with the right arm resting comfortably on a table and the pad of the right index finger over the contactor. The subjects wore sound-attenuating ear muffs (without an auditory masker) to minimize the distractions from ambient noise in the room. At no time during stimulation was the vibrator audible to the subject, for the threshold for audibility of the vibration for all subjects was at least $35 \mathrm{dR}$ above threshold for taction at the highest frequencies (and was even greater at the lower frequencies). The contactor and surround were maintained at a temperature of $37^{\circ} \mathrm{C}$ by placing a heating pad (K-pad) over the contactor between sessions. Before each session the subject adapted the right hand for a minimum of $5 \mathrm{~min}$ by placing it on the heating pad; during stimulation the pad was removed from the contactor and placed under the palm of the hand.

The psychophysical procedure was two-interval-forced-choice. On each trial the subject was instructed to indicate in which of two successive intervals the test stimulus occurred, by pressing one of two buttons located on a box on the table in front of him/her. Each interval 

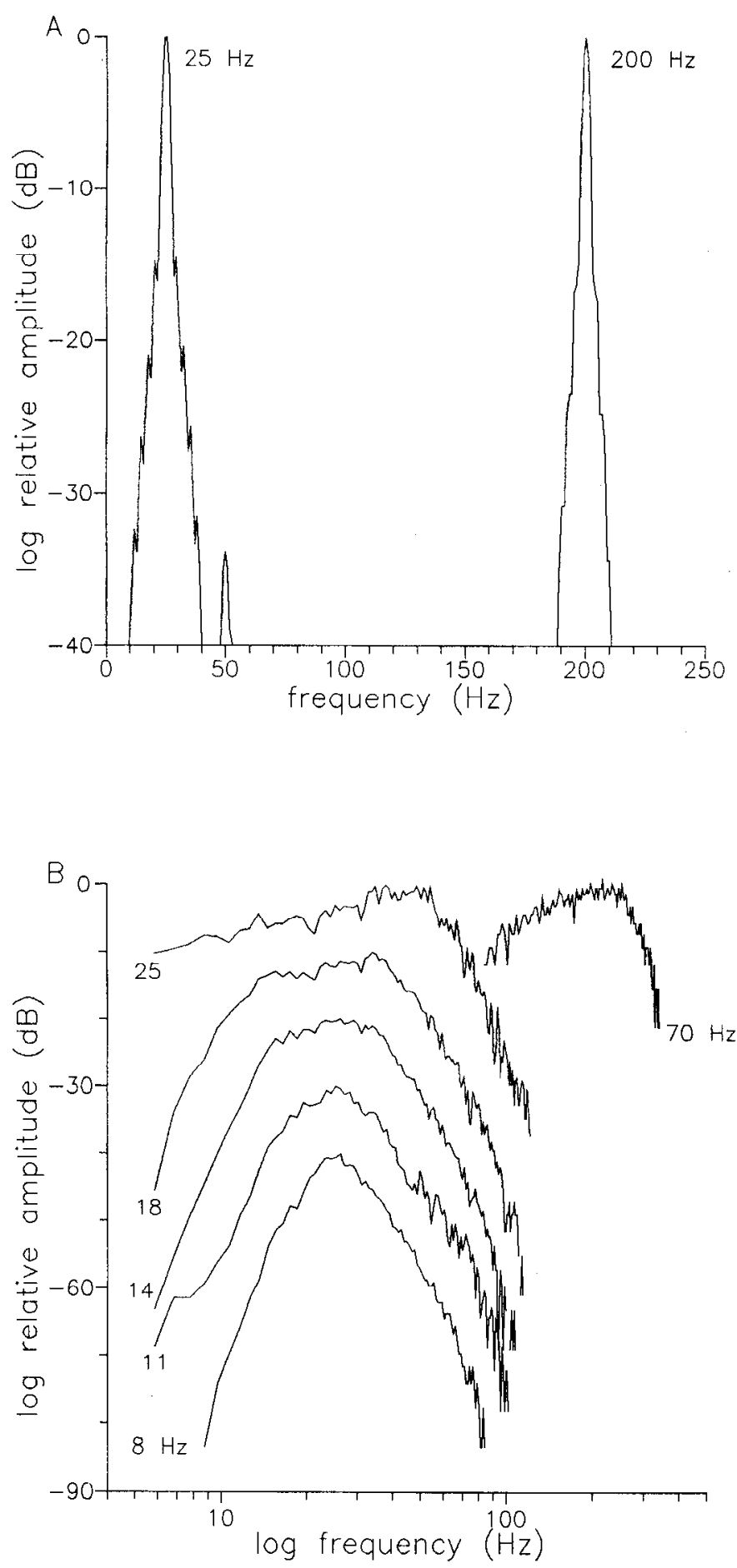

Figure 2. Spectra of sinusoidal and noise stimuli. $A$, Spectra of the $25 \mathrm{~Hz}$ and $200 \mathrm{~Hz}$ sinusoidal stimuli. $B$, Representative noise spectra have been displaced vertically by $10 \mathrm{~dB}$ for clarity. The bandwidth $(-3$ $\mathrm{dB}$ points) of the stimuli ranged from 8 to $70 \mathrm{~Hz}$ (see labels), whereas the peak frequencies ranged from 25 to $55 \mathrm{~Hz}$. The high frequency noise was centered at $218 \mathrm{~Hz}$. All noise spectra have been arbitrarily truncated above the noise floor.

was $400 \mathrm{msec}$ long, and there was a $500 \mathrm{msec}$ delay between intervals. The delay between trials was $10 \mathrm{sec}$, and the occurrence of each interval was denoted by a light emitting diode (LED) on the response box. The LED also provided feedback to the subject, indicating whether a response was correct or incorrect. Another LED provided the same information to the experimenter, who entered the subject's response into a computer. The subject also provided a verbal response by indicating

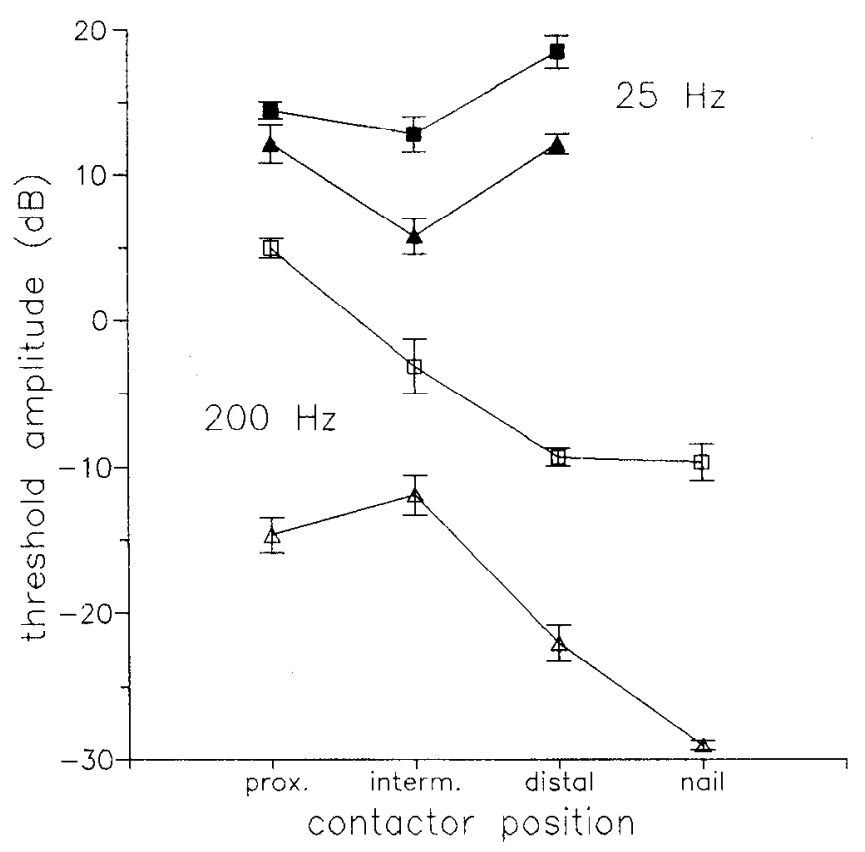

Figure 3. Effects of contactor position on vibrotactile thresholds for two subjects. The stimulus frequencies were $25 \mathrm{~Hz}$ (solid symbols) and $200 \mathrm{~Hz}$ (open symbols), and the subjects were S1 (triangles) and S3 (squares). All stimuli were distal to the DIP joint of the right index finger, and the locations were: proximal ( $p r o x$. ), intenmediate (interm.), distal, and on the end of the nail. Error bars represent 1 SEM.

whether she/he made a correct or incorrect judgment. The timing of the stimuli was under computer control.

The amplitude of the stimulus during a threshold determination was controlled manually by the experimenter through a variable decade attenuator (Leader Instruments Corp., Hauppauge, NY), while the stimulus amplitude for each trial was chosen by computer in a modified tracking procedure (QUEST, Watson and Pelli, 1983). Following two suprathreshold stimulus levels, this algorithm put each stimulus at the most probable estimate of threshold, based on the subject's previous responses to all the stimuli presented during that threshold determination. The first stimulus of each session was placed at about $15 \mathrm{~dB}$ above the expected threshold, and the second stimulus was usually between 3 and $6 \mathrm{~dB}$ above the threshold estimate. After each response, the algo rithm recalculated the threshold estimate, and this continued until the distribution of responses was such that the $97.5 \%$ confidence interval for the threshold estimate was $\leq 4 \mathrm{~dB}$. Threshold was defined as $92 \%$ correct, and it typically took $35-40$ trials, or about $7 \mathrm{~min}$, to obtain one threshold determination. The order of presentation of the stimulus conditions was random (sampled without replacement) such that no stimulus condition was given twice on the same day to the same subject. Typically a subject would run three to five threshold determinations a day, with a 5-10 min rest between each determination.

The index finger was chosen as the stimulation site, in contrast to the more frequently used thenar eminence, because the finger is more typically used to explore one's environment. To select a standard position for the index finger on the contactor, the effect of finger position on detection thresholds of $25 \mathrm{~Hz}$ and $200 \mathrm{~Hz}$ stimuli was measured in two subjects. All finger positions were restricted to glabrous skin distal to the distal interphalangeal (DIP) joint. Subjects placed the finger on the contactor either proximally (near the DIP joint), at an intermediate position (1-2 mm distal to the center of the pad), or at a distal (near the nail) position. Subjects also placed the end of the finger-nail on the contactor, parallel to the long axis of the finger, for the $200 \mathrm{~Hz}$ condition.

The results of the finger position experiment are shown in Figure 3 Both subjects showed a significant effect of finger position on threshold for $200 \mathrm{~Hz}(p<0.01)$ and for $25 \mathrm{~Hz}(p<0.05)$. As the contactor was moved more distally on the fingertip, the sensitivity to $200 \mathrm{~Hz}$ increased by $14.3 \mathrm{~dB}$ for subject 1 and by $12.8 \mathrm{~dB}$ for subject 3 . The finger-nail was the most sensitive part of the finger in response to the $200 \mathrm{~Hz}$ 


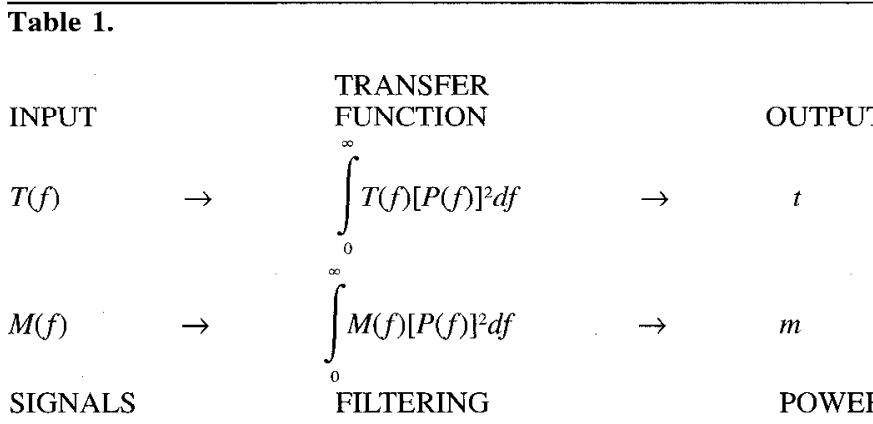

$T=$ test stimulus power, $M=$ masker power, $f=$ frequency $(\mathrm{Hz}), P=$ Pacinian channel, $t=$ power of test passed through filter at threshold, and $m=$ power of masker passed through filter.

stimulus. This may be due to the spatial summation exhibited by $\mathrm{Pa}$ cinian corpuscles (Verrillo, 1963). That is, when the nail was stimulated, there was no surround to prevent spread of the stimulus to tissue surrounding the nail. In contrast, the distal position was not the most sensitive to $25 \mathrm{IIz}$.

To prevent the spread of excitation to the nail, a proximal contactor position was desirable. Therefore, we chose to stimulate the intermediate position of the finger, $1-2 \mathrm{~mm}$ distal to the center of the pad.

Data analysis. We used a Gaussian function to model the results from the three subjects $(\mathrm{S} 1, \mathrm{~S} 2, \mathrm{~S} 3)$ who participated in the masking experiments:

$$
\log \text { threshold }(\mathrm{dB})=\alpha-\delta \cdot e^{-\left(\frac{\beta-\log f}{\gamma}\right)^{2}},
$$

where, $f=$ frequency $(\mathrm{Hz})$ and $\alpha, \beta, \gamma$, and $\delta$ are free parameters. Gaussian filters have been used successfully to model both temporal (Mandler and Makous, 1984) and spatial (Wilson and Gelb, 1984) channels in the visual system. For all the masking experiments, the P-channel was modeled as a filter $[P(f)]^{2}$ that integrates the power of the stimuli passing through it (see Fig. 5B; Patterson, 1974, 1976). To accomplish this, the shape of the filter between 65 and $400 \mathrm{~Hz}$ was derived for each subject by fitting Equation 2 to his threshold frequency characteristic (see above), squaring each point and multiplying by $f^{2}$ to get the power at each point. The function was then inverted, and the peak sensitivity was set equal to one. The actual spectra of the test $[T(f)]$ and the masker $[M(f)]$ were used in the computations, and the relative power of these stimuli were specified by their respective mean squared amplitudes. The output of the filter was computed by integrating the cross product of the power spectrum of the stimulus and the filter. The $f^{2}$ terms canceled when the spectra were multiplied by the reciprocal of threshold, and therefore are not shown. This is restated in analytical form in Table 1 and Equations 3 and 4 (see Zwislocki, 1965, for a review of equations).

Then the signal power and noise power passing through the $\mathrm{P}$-channel were expressed as a ratio: $k=t /\left(m+n_{i}\right)=$ signal/noise $=$ constant at threshold, where $n_{i}=$ the internal noise within the channel. Rearranging yields

$$
t=k\left(m+n_{i}\right) .
$$

Expressing the threshold shift in $\mathrm{dB}$, we get

$$
\text { threshold shift } \begin{aligned}
(\mathrm{dB}) & =10 \log \left(\frac{t}{t_{0}}\right) \\
& =10 \log \left[\frac{k\left(m+n_{i}\right)}{t_{0}}\right]
\end{aligned}
$$

where $t_{0}=$ the power of the test at absolute threshold (no masker).

If the channel behaves in the same way as a critical band, then the threshold of a signal within that channel should be determined by the ratio between the signal power and the noise power (masker) passing through the channel (Fletcher, 1940; Miller, 1947; Hamilton, 1957; Green and Swets, 1966; Patterson, 1974, 1976). We assumed that this ratio is constant at detection threshold.

Equation 4 was fit to all the masking functions, given the filter shape derived for each subject from Equation 2. For statistical analysis, the

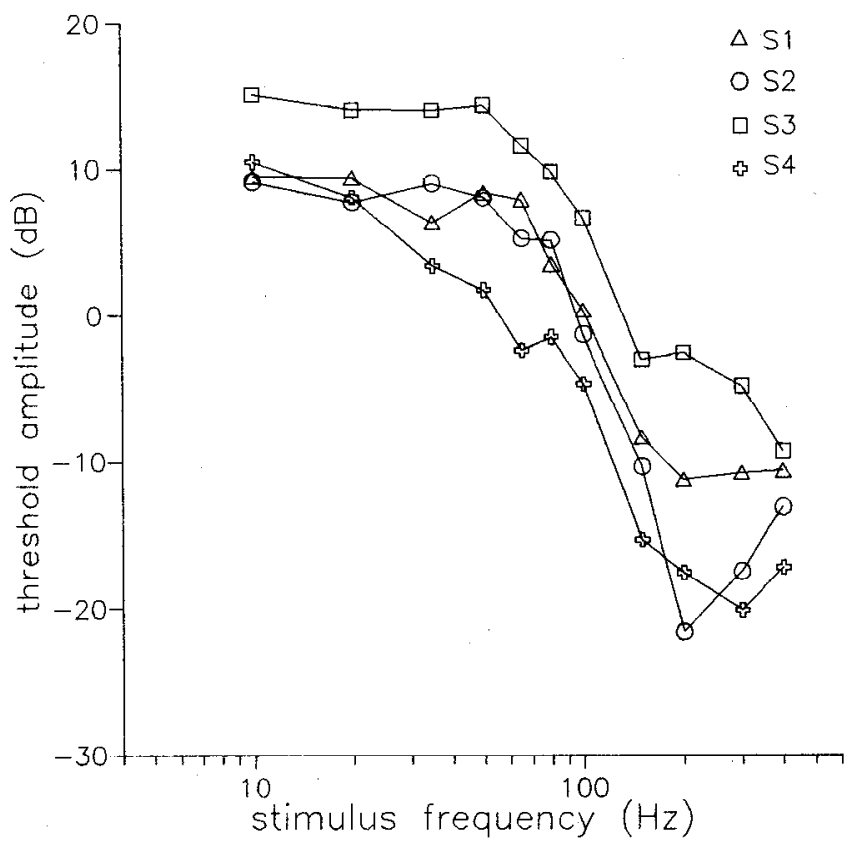

Figure 4. Detection thresholds as a function of stimulus frequency. Four subjects $(S 1-S 4)$ were tested at frequencies between 10 and 400 $\mathrm{Hz}$. Each point represents the mean of three threshold determinations. The SEM ranged from 0.27 to $2.63 \mathrm{~dB}$ with a median of $0.82 \mathrm{~dB}$.

sum of squared deviations of the data from each curve were computed. The ratio between the squared deviations for any two curves were then computed and tested for significance by an $F$ test.

\section{Results}

The results of subjects 1 and 2 are shown consistently throughout the Results section since they were the only subjects that were tested in all of the masking conditions. In instances in which subject 3 was also used, his results are reported in the text. Subject 4 was only used in the first experiment (threshold as a function of frequency) to validate the technique.

\section{Threshold versus frequency}

The first experiment was designed to compare our findings on the fingertip with previous findings from the thenar eminence and to measure the shape of the threshold-frequency characteristic for each subject. The threshold-frequency characteristic from each subject was used later to model the results of the masking experiments from each subject. Figure 4 shows the results of this experiment for the four subjects (S1-S4). Three of four subjects showed little change in sensitivity in the low frequency region between 10 and $50 \mathrm{~Hz}$. This was followed by a region in which sensitivity increased (about $16 \mathrm{~dB} /$ octave) between 65 and $150 \mathrm{~Hz}$ and peaked between 200 and $400 \mathrm{~Hz}$. Subject 4 (female) showed a more gradual increase in sensitivity than the other three subjects. The oldest subject (S3) had the highest overall thresholds.

\section{ON-frequency masking}

In the ON-frequency masking experiment (experiment 2), the test stimulus and masking stimulus occupied the same frequency region, above $50 \mathrm{~Hz}$ where the Pacinian corpuscle mediates threshold sensitivity (Verrillo, 1963; Bolanowski and Verrillo, 1982; Bolanowski et al., 1988). Three subjects (S1, S2, S3) participated in this experiment that was designed to measure the 
signal-to-noise ratio $(\mathrm{S} / \mathrm{N})$ at threshold within the P-channel. This was accomplished through the use of a simultaneous noise masker (centered at $218 \mathrm{~Hz}$ ) and a $200 \mathrm{~Hz}$ sinusoidal test. The level of the masker was varied between 0 and $30 \mathrm{~dB} \mathrm{SL}$. The results of this experiment, taken together with the knowledge (from the first experiment) of the shape of the P-channel for each subject in the region between 65 and $200 \mathrm{~Hz}$ (Fig. 5A), allowed the calculation of the S/N (see Materials and Methods). This concept is depicted graphically in Figure $5 B$ and analytically in Equation 3.

The results of the $\mathrm{ON}$-frequency masking experiment are shown for two subjects (S1, S2) in Figure 6. Each point represents one threshold determination at each masker level. The points clustered around a straight line. By fitting Equation 4 to the results we can determine the $\mathrm{S} / \mathrm{N}$ ratio $(k)$ and the internal noise $\left(n_{i}\right.$; see also Eq. 3). The values of $k$ were $1.20,1.15$, and 0.63 , and the values of $n_{i}$ were $0.0,0.0$, and 0.02 for S1, S2, and $\mathrm{S} 3$, respectively.

\section{OFF-frequency masking}

Since the shape of the P-channel below $50 \mathrm{~Hz}$ cannot be measured directly, its shape must be inferred either from masking or adaptation experiments. Previously, forward masking and adaptation studies have been used to estimate the shape of the P-channel below $50 \mathrm{~Hz}$ (at suprathreshold levels) and found it to be an extrapolation of the linear portion of the curve (between 150 and $65 \mathrm{~Hz}$ ) to lower frequencies (Verrillo and Gescheider, 1977; Gescheider et al., 1983). This is shown in Figure 5A for subject 1 . In the present study, we employed simultaneous masking to confirm and extend the previous findings.

The results from the ON-frequency masking experiment were used to model the results of a third experiment involving OFFfrequency masking (Figs. 7-9). In this experiment, the test $(200$ $\mathrm{Hz}$ sinusoid) and the masker (25-55 Hz center frequencies; 8$25 \mathrm{~Hz} \mathrm{BWs}$; see Figure 2 for spectra) occupied different frequency regions (Fig. 7). The objective was to determine the shape of the P-channel in the region from 10 to $65 \mathrm{~Hz}$ by varying the spectrum of the masker within this region.

OFF-frequency masking functions were obtained for each of the five bandwidths of noise (results from four are shown since the results from the fifth $\mathrm{BW}$ were qualitatively similar). The masker level was varied from 0 to $30 \mathrm{~dB} \mathrm{SL}$, and the threshold for detection of a $200 \mathrm{~Hz}$ sinusoid was measured. Subjects 1, 2, and 3 participated in this experiment, but the results from $\mathrm{S} 1$ and $S 2$ are shown. The results from S3 were similar. For the narrowest masker $\mathrm{BW}(8 \mathrm{~Hz})$, masking did not begin to elevate the threshold of the $200 \mathrm{~Hz}$ test stimulus until the masker was nearly $20 \mathrm{~dB}$ above detection threshold (Figs. $8 A, 9 A$ ), whereas the broadest masker $\mathrm{BW}(25 \mathrm{~Hz} \mathrm{BW})$ began to mask the test between 10 and $15 \mathrm{~dB}$ above threshold (Fig. $8 D, 9 D$ ). This is consistent with the idea that the test threshold was affected by the masker power at frequencies to which the P-channel was sensitive. This is also exemplified by an increase in the amount of masking with increases in masker BW, at a given masker level.

To further assess the critical band model, Equation 4 was fit to each of the masking functions obtained from the OFF-frequency masking experiment (Figs. 8, 9). In fitting these functions, $k(\mathrm{~S} / \mathrm{N})$ was held constant for each subject at the value previously determined from the $\mathrm{ON}$-frequency masking experiments. The variable $k$ was held constant in order to determine the shape of the P-channel in the region between 10 and $65 \mathrm{~Hz}$.
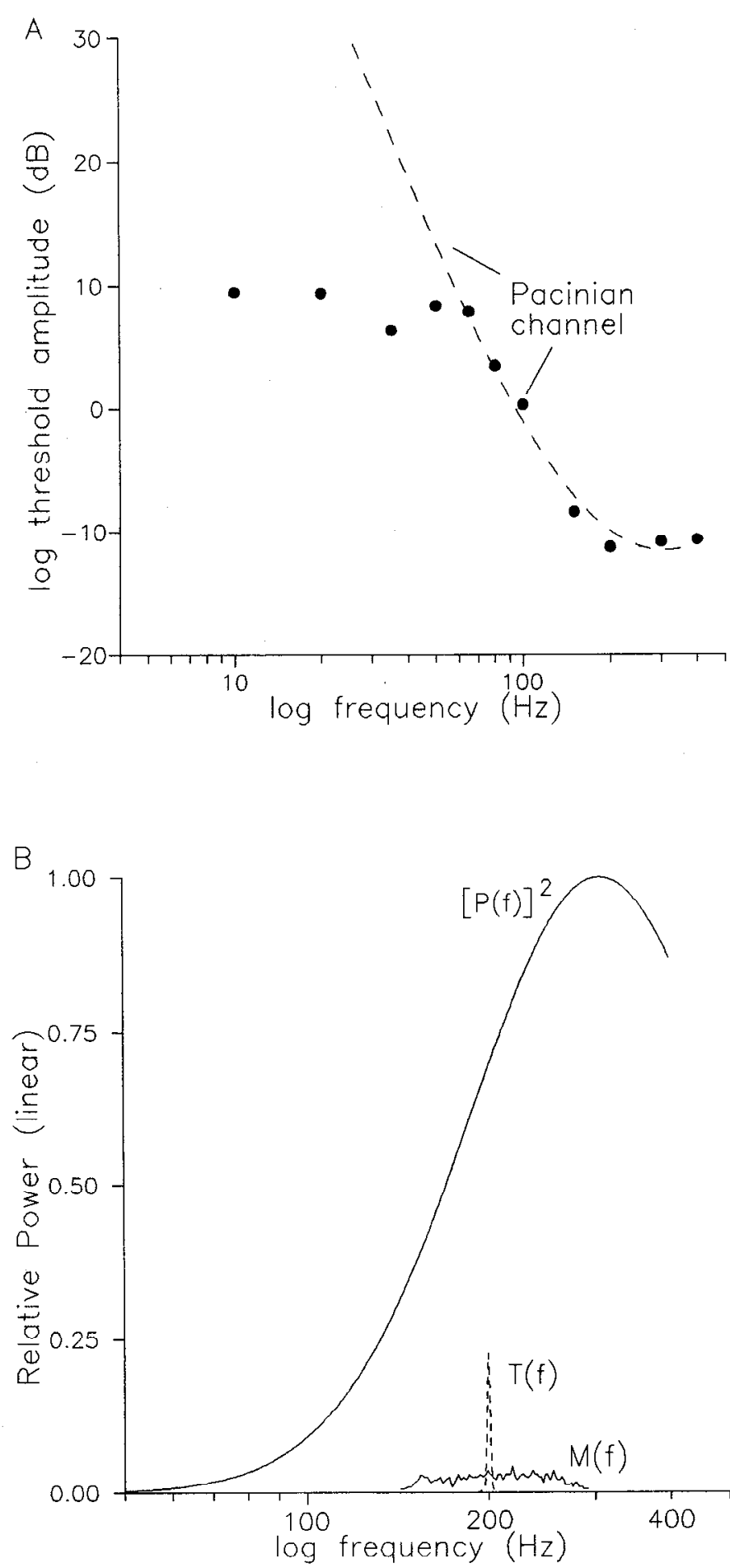

Figure 5. Methodology used to model the ON-frequency masking experiments. $A$, The hypothetical shape of the Pacinian channel derived from previous work (Verrillo and Gescheider, 1977; Gescheider et al., 1983; dashed line) is plotted over the threshold values obtained for S1 [solid circles; Eq. 2 (Gaussian) was fit to the thresholds and to a linear extrapolation of the data in the region between 65 and $150 \mathrm{~Hz}] . B$, To model the threshold function as a filter, the threshold function of the P-channel $[P(\Omega)]$ was inverted, the peak sensitivity was set equal to one and the function was then squared. Spectra of the test $[T(f)]$ and the masker $[M(f)]$ are also shown (see Materials and Methods for equations). Note that the ordinate scale is linear. 

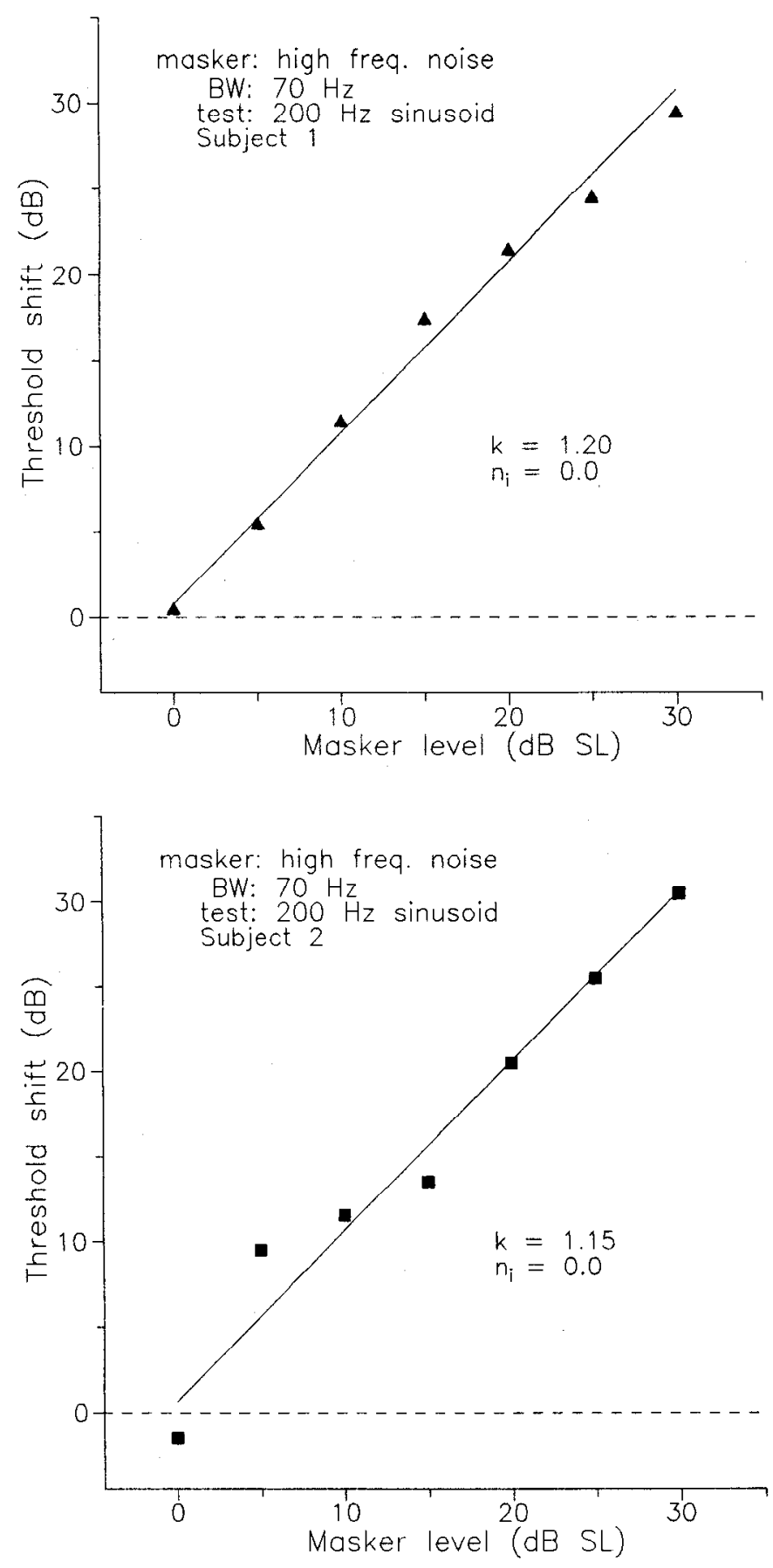

Figure 6. Results of the ON-frequency masking experiment. The results from S1 (top) and S2 (bottom) are shown. Each point represents one threshold determination. The test stimulus was a $200 \mathrm{~Hz}$ simusoid, while the masker was high frequency noise centered a $218 \mathrm{~Hz}$. The values $k$ and $n_{i}$ correspond to the $\mathrm{S} / \mathrm{N}$ at threshold and internal noise, respectively, derived from the best fit of Equation 4 to the results.

The internal noise ( $n_{i}$; in Eq. 4 ), and the shape of the P-channel (Eq. 2) were varied to minimize the difference (sum of squared deviations) between the fit of Equation 4 and the data at all the masker bandwidths. The internal noise was allowed to vary, since the shapes of the masking functions differed between the $\mathrm{ON}$ - and OFF-frequency masking experiments. The free parameter $n_{i}$ showed no significant variation across conditions (i.e., masker bandwidths), and therefore the mean internal noise for the OFF-frequency masking experiments was computed for each

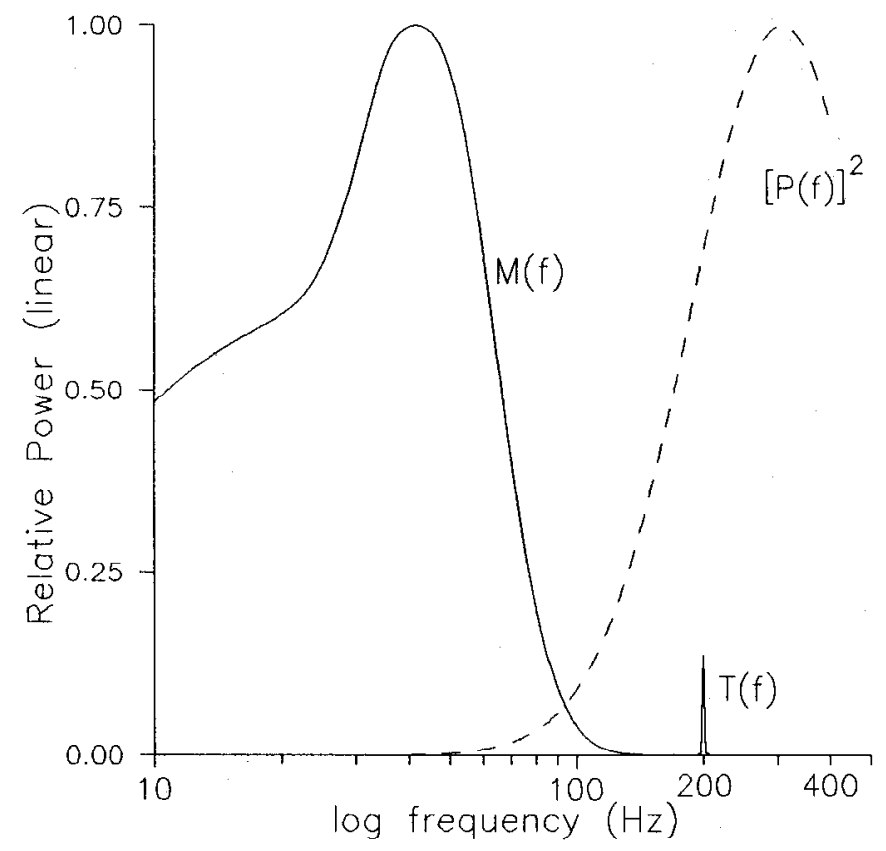

Figure 7. Methodology used to model the OFF-frequency masking experiments. In these experiments, the test $[T(f)]$ and masker $[M(f)]$ occupied different frequency regions. The noise masker is shown as a smoothed representation of the $25 \mathrm{~Hz} \mathrm{BW}$ shown in Figure 2. Note that the ordinate is lincar. The shape of the P-channcl (dashed line; $\left.[P(f)]^{2}\right)$ was Gaussian (Eq. 2).

subject $(\mathrm{S} 1=0.063, \mathrm{~S} 2=0.023, \mathrm{~S} 3=0.11)$. The internal noise estimates from $\mathrm{OFF}$-frequency masking were significantly greater than the internal noise estimates from $\mathrm{ON}$-frequency masking for subjects 1 and $2(p<0.01)$ but not for S3. The mean $n_{i}$ and the best shape of the P-channel (Eq. 2) for each subject were then used to fit the masking functions in Figures 8 and 9 (solid lines). This provided a single fit of Equation 4 to all the OFFfrequency masking functions for each subject, regardless of the masker bandwidth. This fit did not differ significantly from the best fit of Equation 4 to each individual OFF-frequency masking function (where $k$ and $n_{i}$ were free to vary) in all instances.

One aspect of the data was not accounted for by the model. Subjects 1 and 2 showed a small amount $(1-3 \mathrm{~dB})$ of negative masking (i.e., the masker actually led to an improvement in the detection of the test) near threshold levels of the masker. For S1 (Fig. 8), negative masking occurred at the $5 \mathrm{~dB}$ SL masker level, and for S2 (Fig. 9), it occurred at the $0 \mathrm{~dB}$ SI. masker level. This effect was not apparent in S3.

The shape of the P-channel that best fit the data in Figures 8 and 9 is shown in Figure $10, A$ and $B$. This curvilinear form of the channel fit the OFF-frequency masking results significantly better than the previous model in only one of the three subjects (S2: $F=5.35$, df $=34, p<0.01$; see Fig. $5 A$; Bolanowski et al., 1988). The results from $S 3$ showed only a small trend towards a curvilinear P-channel in the region below $50 \mathrm{~Hz}$ (Fig. $10 C$ ). When the data from the three subjects were taken together, there was not a significant difference between the goodness of fit of the current shape of the P-channel and the previous shape (compare Fig. $5 A$ to Fig. 10). This curvilinear shape reflects the best fit of the model when the shape of the channel was free to vary, but it does not imply a significant improvement over the previous model. 
Figure 8. The results of the OFF-frequency masking experiments. The results from SI are shown for four of the five bandwidths used in this experiment. $A, 8 \mathrm{~Hz}$ BW. $B, 10 \mathrm{~Hz} \mathrm{BW}$. $C$, $18 \mathrm{~Hz}$ BW. $D, 25 \mathrm{~Hz}$ BW. Each point is the mean of three threshold determinations $( \pm$ SEM). The results were modeled as described in the text. Equation 4 was fit to the results while holding $k$ constant and letting $n_{i}$ and the shape of the P-channel (not shown) vary. Subsequently, a single version of Equation 4 (solid curve) was fit to all the masking functions after arriving at the shape of the P-channel shown in Figure $10 \mathrm{~A}$ and at the values of 1.20 and 0.063 , for $k$ and $n_{i}$, respectively. This single fit of Equation 4 to all the OFF-frequency masking functions accounted for $95.4 \%$ of the variance in the best cases ( 18 and $25 \mathrm{~Hz}$ BWs) and $77.5 \%$ of the variance in the worst case (10 Hz BW).
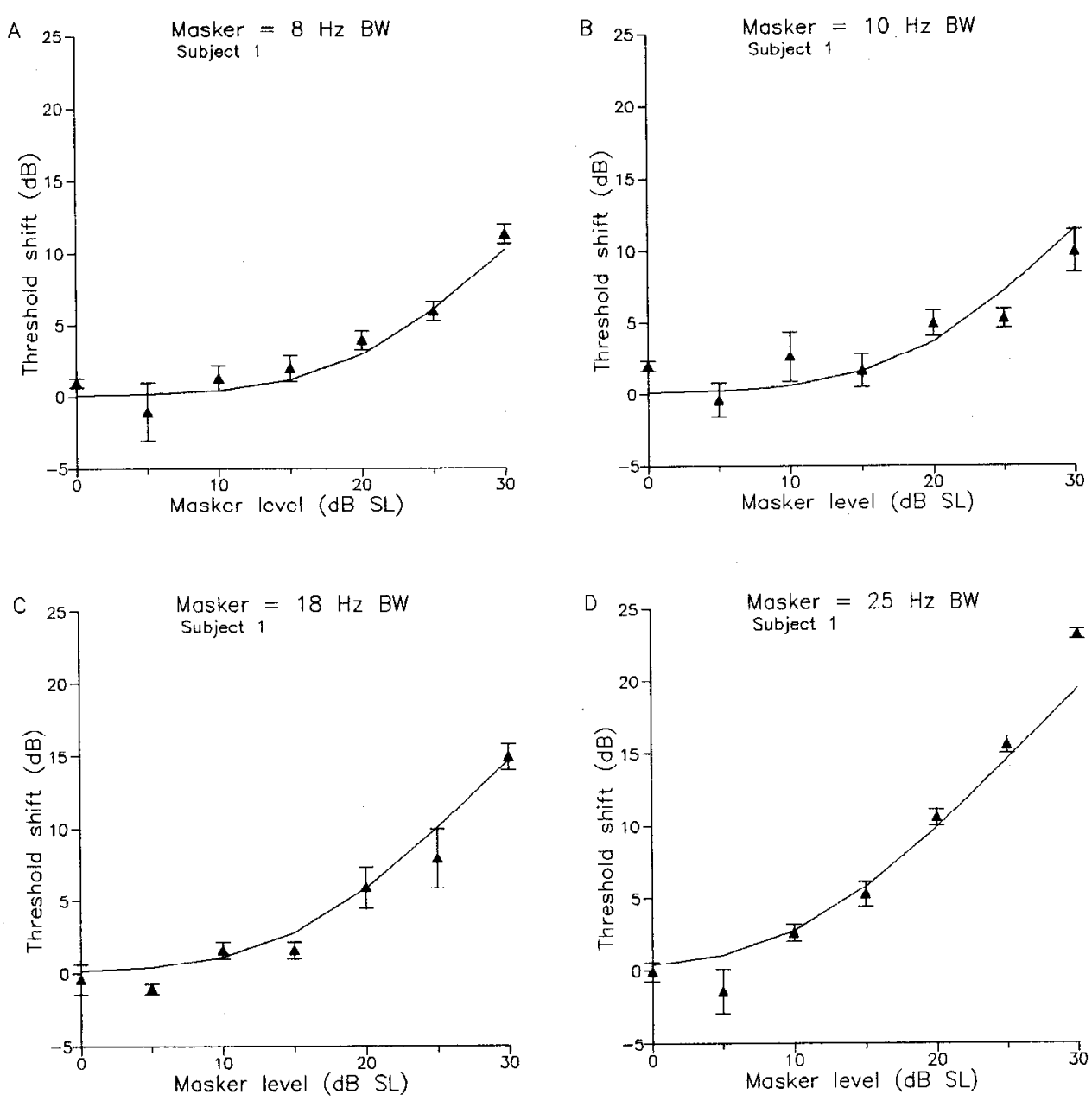

\section{A test of the model}

If the parameters $k$ and $n_{i}$ can be measured for each subject, and then treated as constants in a particular class of experimental conditions (e.g., OFF-frequency masking), then the model would serve to predict the outcome of all experiments in this class. By conducting another OFF-frequency masking experiment (experiment 4) with different stimuli, we hoped to predict the results with no free parameters. The test stimulus was the high frequency noise centered at $218 \mathrm{~Hz}$ (used as a masker for the ONfrequency masking experiment), and the masking stimulus was a $25 \mathrm{~Hz}$ sinusoid. Two subjects ( $\mathrm{S} 1$ and S2) participated in the fourth experiment.

The results of this experiment are shown in Figure 11 and are similar to the results of the earlier OFF-frequency masking experiment. Both subjects began to show significant changes in threshold with increases in the masker level above $15 \mathrm{~dB}$ SL. Equation 4 was fit to the masking functions with no free parameters; the shape of the P-channel and the values of $k$ and $n_{i}$ for each subject were taken from both of the earlier masking experiments. This fit does not differ significantly from the best fit of Equation 4 to the masking functions when all parameters were allowed to vary. The best fit accounted for $98.6 \%$ of the variance for $\mathrm{S} 1$ and $96.6 \%$ for $\mathrm{S} 2$, whereas the parameter free fit accounted for $97.7 \%$ for $\mathrm{S} 1$ and $95.5 \%$ for $\mathrm{S} 2$.

\section{Discussion}

\section{General discussion}

The results presented here require the existence of at least two independent channels in the somatosensory system, and they are consistent with a model in which the channel mediated by the Pacinian corpuscle integrates the power of the stimulus activating it. These results are analogous to previous findings in other sensory systems. The visual system appears to process information in color opponent (DeValois and DeValois, 1975; Hurvich, 1981), spatial frequency (Camphell and Robson, 1968; Blakemore and Campbell, 1969; Graham and Nachmias, 1971; Wilson and Gelb, 1984; Shapley and Lennie, 1985; Graham, 1989), and temporal frequency (Watson and Robson, 1981; Mandler and Makous, 1984; Waugh and Hess, 1994) channels. The auditory system processes frequency information across critical band filters and integrates the energy within each critical band (Hawkins and Stevens, 1950; Zwicker et al., 1957; Greenwood, 1961; Scharf, 1970; Patterson, 1974, 1976). Thus, it appears that the senses of vision, audition, and touch filter incoming stimuli into separate channels.

The concept of information passing up the neuraxis in parallel channels or pathways is rudimentary to our understanding of sensory processing (Müller, 1838; cit. Dennis, 1948; Lennie, 1980). This concept has been successfully applied to the visual system in the context of color vision. That the individual cone types at the periphery combine at later stages in the visual system ultimately rendering a unified percept, is the basis for our current understanding of color vision and color-opponent mechanisms (Hurvich, 1981; Lennie and D'Zmura, 1988). Furthermore, without individual channels, the system would be incapable of discriminations along more than one continuum, since 

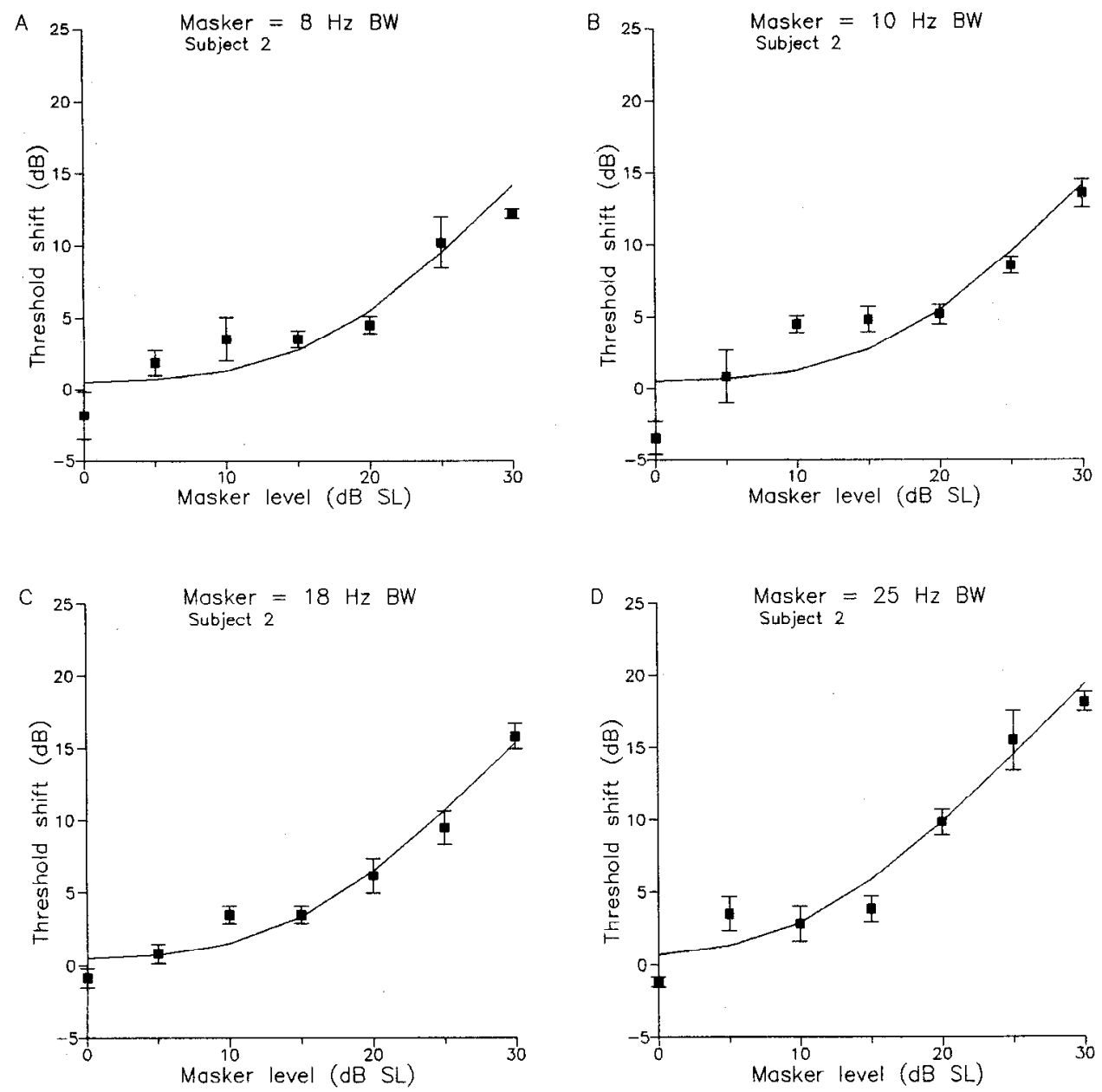

Figure 9. The results of the OFF-frequency masking experiments. The results from S2 are shown for four of the five bandwidths used in this experiment. $A, 8 \mathrm{~Hz}$ BW. $B, 10 \mathrm{~Hz}$ BW. $C$, $18 \mathrm{~Hz}$ BW. $D, 25 \mathrm{~Hz}$ BW. See Figure 8 for further details. Equation 4 (solid curve) was fit to all the masking functions after arriving at the shape of the P-channel shown in Figure $10 B$ and at the values of 1.15 and 0.023 , for $k$ and $n_{i}$, respectively. This single fit of Equation 4 to all the OFF-frequency masking functions accounted for $96.2 \%$ of the variance in the best case $(18 \mathrm{~Hz}$ BW) and $81.6 \%$ of the variance in the worst case $(10 \mathrm{~Hz} \mathrm{BW})$.

it would be constrained by a univariate response (Rushton, 1972).

One of the subjects (S2) showed a significant difference in the shape of the P-channel from earlier measures of its shape (Verrillo and Gescheider, 1977; Gescheider et al., 1983). This result raises three possibilities. (1) It is possible that there are meaningful differences in channel shape among individual subjects, as argued by Van Doren (1990), and that averaging across subjects in earlier studies (Verrillo and Gescheider, 1977; Gescheider et al., 1983; Bolanowski et al., 1988) tends to mask these differences. (2) It is also possible that the low frequency masker in the OFF-frequency masking condition affected the shape of the P-channel in this region, through some sort of channel interaction. One such channel interaction would be an alteration of the S/N of the P-channel at threshold in the presence of the low frequency masker. Unfortunately, the shape of the channel cannot be determined without holding the $\mathrm{S} / \mathrm{N}$ constant, as in the current experiment. (3) Another possibility is that the P-channel does not integrate the power of the stimulus at low frequencies, but rather approximates this process. However, given that the model accounts for the results of all masker BWs, ranging from a $25 \mathrm{~Hz}$ sinusoid to a band-limited noise centered at $50 \mathrm{~Hz}$, the most parsimonious interpretation of the results is that power activating the channel is integrated. If the channel did not integrate the power, it is unlikely that the results from so many conditions (i.e., BWs) could be accounted for by one curve.

\section{Comparison to previous studies}

Other investigators have used the techniques of forward masking (Gescheider et al., 1983) and adaptation (Verrillo and Gescheider, 1977; Hollins et al., 1990), in conjunction with the manipulation of stimulus size (Verrillo, 1963) and temperature (Bolanowski and Verrillo, 1982), to formulate a four channel model for touch (Bolanowski et al., 1988). These investigators have related the operating ranges and sensitivities of four psychophysical channels in glabrous skin to temporal and spatial parameters of the stimulus. The authors postulated that each channel originates peripherally at a distinct receptor complex. The results presented here are consistent with this model, since we found evidence for independence of the Pacinian channel. One caveat, however, is that the Pacinian channel is not entirely independent, insofar as the low frequency masker added noise to the P-channel in two of the three subjects. That is, thcre was a significant increase in the internal noise of the P-channel in the OFF-frequency masking condition, compared to the ON-frequency condition for subjects 1 and 2 .

Two previous studies have used the simultaneous masking technique in touch. Hamer et al. (1983) used a low frequency noise to mask a $200 \mathrm{~Hz}$ sinusoid, and they predicted break points in the masking functions (masker level at which masking begins) based on a linear extrapolation of the P-channel (e.g., see Fig. 5A). Labs et al. (1978) also uscd a simultancous masking technique with a sinusoidal masker and sinusoidal test to estimate 

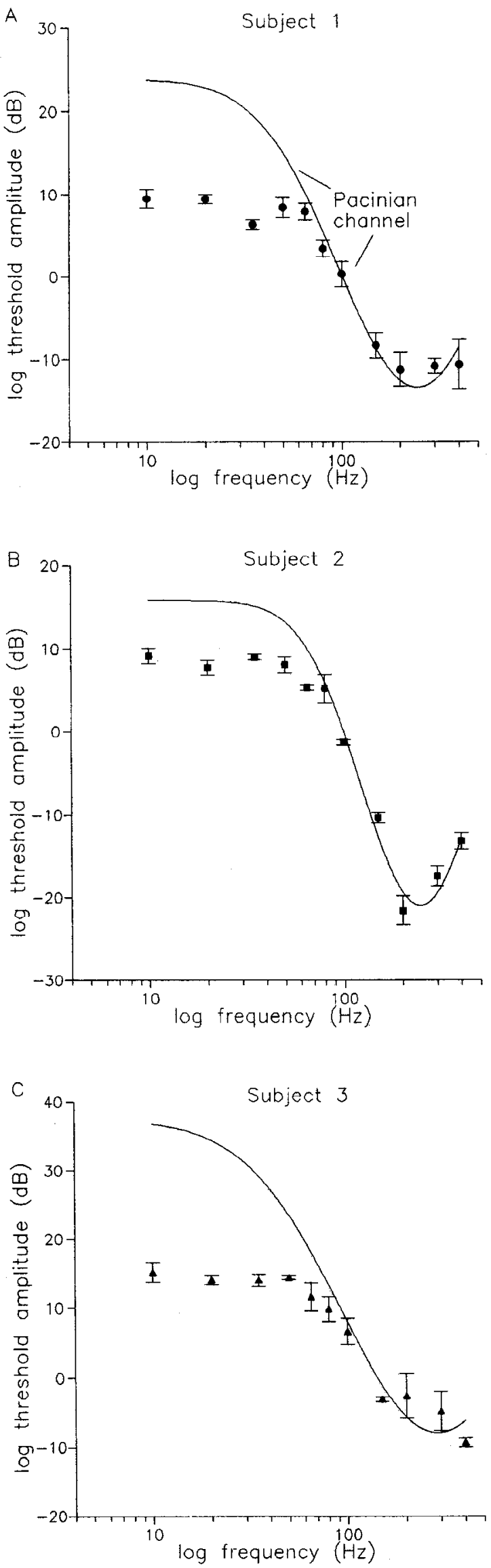

Figure 10. Shapes of the P-channel, derived from the OFF-frequency masking experiment. The results are shown for three subjects [S1 $(A)$, the shape of the P-channel, and they obtained a similar shape. Both of these findings are consistent with the idea that the P-channel is independent from the other channels.

Two earlier studies have treated the Pacinian channel as a critical band. Verrillo and Gescheider (1975) had subjects match the subjective intensity of two stimuli activating the P-channel with a third stimulus activating the same channel. They then compared this result to a condition in which the subjects matched the intensity of two stimuli activating the P-channel to a third stimulus not activating the P-channel. They found that the results for two frequencies within the P-channel were comparable to those within an auditory critical band showing energy summation. However, when one stimulus was within, and the other was outside of the P-channel, the matching functions exhibited loudness summation, comparable to loudness summation typically found across critical bands. Marks (1979) also obtained a similar finding when he looked at magnitude estimation functions of sinusoidal stimuli within and outside of the P-channel. He observed energy summation within the P-channel and loudness summation across channels. These results, in conjunction with the current findings, strongly support the notion that the P-channel exhibits characteristics that are analogous to those found in critical bands within the auditory system.

One difference between the four channel model (Bolanowski et al., 1988) and the present one is the postulated slope of the low frequency portion of the P-channel between 150 and $65 \mathrm{~Hz}$. The previous findings obtained on the thenar eminence showed the slope of the P-channel in this region to be $-12 \mathrm{~dB} /$ octave. We found the average slope to be $-16 \mathrm{~dB} /$ octave. This might have resulted from differences in stimulus locations, since we stimulated the distal pad of the index finger, where there are nearly twice the density of Pacinian corpuscles as in the thenar eminence (Johansson and Vallbo, 1979). It may also have arisen from our subject pool, since one subject (S4) showed a more gradual slope in the region between 65 and $150 \mathrm{~Hz}$-more comparable to that found on the thenar eminence. One other study found a $-12 \mathrm{~dB} /$ octave slope on the middle fingertip (Verrillo, 1971). However, Verrillo used a $0.005 \mathrm{~cm}^{2}$ contactor, whereas our contactor was $0.13 \mathrm{~cm}^{2}$, suggesting that spatial aspects of the stimulus may be important (see also Verrillo, 1963).

\section{Conclusion}

The current study employed vibrotactile stimuli to assess the psychophysical independence of the Pacinian channel from the other tactile channels. We used simultaneous masking of a sinusoidal stimulus with band-limited noise and demonstrated that the channel mediated by Pacinian corpuscles is analogous to a critical band in the auditory system. The Pacinian channel filters and integrates stinuli that fall within the pass-band of the channel. The threshold of a test signal was determined by the signalto-noise ratio of the test and the masker power within the passband, whereas masker power falling outside of the pass-band had no effect on the threshold of the test.

$\leftarrow$

$\mathrm{S} 2(B)$, and $\mathrm{S} 3(C)]$. The solid symbols are the mean of three threshold measurements $( \pm$ SEM) for individual sinusoids in the absence of a masker (from Fig. 4). The solid lines correspond to the shape of the P-channel derived by fitting Equation 4 to the OFF-frequency masking experiments and Equation 2 to the threshold-frequency characteristics (see Results for further explanation). 

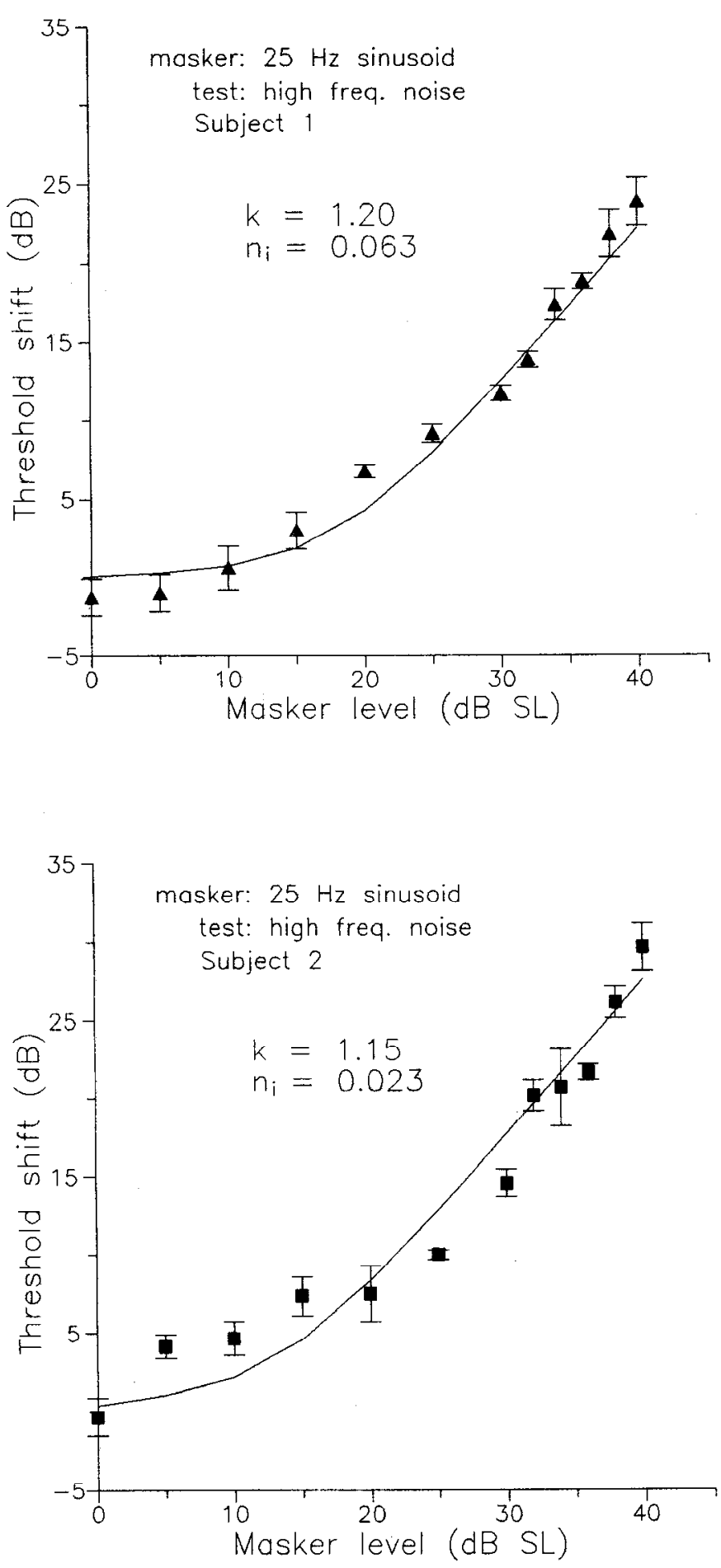

Figure 11. Results from a second set of OFF-frequency masking observations (experiment 4 ), modeled with no free parameters. The results from $\mathrm{S} 1$ (top) and $\mathrm{S} 2$ (bottom) are shown. Each point represents the mean ( \pm SEM) of two to six threshold determinations. The masker was a $25 \mathrm{IIz}$ sinusoid, and the test was high frequency noisc $(218 \mathrm{~Hz}$ center frequency, $70 \mathrm{~Hz} \mathrm{BW}$ ). Equation 4 was used to predict the masking functions (solid lines) with the shapes of the $\mathbf{P}$-channels shown in Figure 10 and with the values for $k$ and $n_{i}$ measured in the earlier experiments. This parameter free fit accounted for $97.7 \%$ of the variance in S1 and $95.5 \%$ of the variance in $\mathbf{S} 2$.

\section{References}

Blakemore C, Campbell FW (1969) On the existence of neurones in the human visual system selectively sensitive to the orientation and size of retinal images. J Physiol (Lond) 203:237-260.

Bolanowski SJ Jr, Verrillo RT (1982) Temperature and criterion effects in a somatosensory subsystem: a neurophysiological and psychophysical study. J Neurophysiol 48:836-855.

Bolanowski SJ Jr, Gescheider GA, Verrillo RT, Checkosky CM (1988) Four channels mediate the mechanical aspects of touch. J Acoust Soc Am 84:1680-1694.

Campbell FW, Robson JG (1968) Application of Fourier analysis to the visibility of gratings. J Physiol (Lond) 197:551-566.

DeValois RL, DeValois KK (1975) Neural coding of color. In: Handbook of perception, Vol 5, Seeing (Carterette EC. Friedman MP, eds). New York: Academic.

Fletcher H (1940) Auditory patterns. Rev Mod Physics 12:47-66.

Gescheider GA, Capraro AJ, Frisina RD, Hamer RD, Verrillo RT (1978) The effects of surround on vibrotactile thresholds. Sensory Proc 2:99-115.

Gescheider GA, O'Malley MJ, Verrillo RT (1983) Vibrotactilc forward masking: evidence for channel independence. J Acoust Soc Am 74: 474-485.

Gescheider GA, Sklar BF, Van Doren CL, Verrillo RT (1985) Vibrotactile forward masking: psychophysical evidence for a triplex theory of cutaneous mechanoreception. J Acoust Soc Am 78:534-543.

Graham N (1989) Visual pattern analyzers. London: Oxford UP.

Graham N, Nachmias J (1971) Detection of grating patterns containing two spatial frequencies: a comparison of single-channel and multiplechannels models. Vision Res 11:251-259.

Green DM, Forrest TG (1986) Profile analysis and background noise. J Acoust Soc Am 80:416-421.

Green DM, Swets JA (1966) Signal detection theory and psychophysics. New York: Wiley.

Greenwood DD (1961) Auditory masking and the critical band. J Acoust Soc Am 33:484-502.

Hamer RD, Verrillo RT, Zwislocki JJ (1983) Vibrotactile masking of Pacinian and non-Pacinian channels. J Acoust Soc Am 73:12931303.

Hamilton PM (1957) Noise masked thresholds as a function of tonal duration and masking noise band width. J Acoust Soc Am 29:506511.

Hawkins JE, Stevens SS (1950) The masking of pure tones and of speech by white noise. J Acoust Soc Am 22:6-13.

Henning GB, Hertz BG, Broadbent DE (1975) Some experiments bearing on the hypothesis that the visual system analyses spatial patterns in independent bands of spatial frequency. Vision Res 15:887-897.

Hollins M, Gobel AK, Whitsel BL, Tommerdahl M (1990) Time course and action spectrum of vibrotactile adaptation. Somatosens Mot Res $7: 205-221$.

Hurvich LM (1981) Color vision. Sunderland, MA: Sinauer.

Johansson RS, Vallbo AB (1979) Taclile sensibility in the human hand: relative and absolute densities of four types of mechanoreceptive units in glabrous skin. J Physiol (Lond) 286:283-300.

Labs SM, Gescheider GA, Fay RR, Lyons CH (1978) Psychophysical tuning curves in vibrotaction. Sensory Proc 2:231-247.

Lennie P (1980) Parallel visual pathways: a review. Vision Res 20: 561-594.

Lennie P, D'Zmura M (1988) Mechanisms of color vision. CRC Crit Rev Nenrobiol 3:333-400.

Mandler MB, Makous W (1984) A three channel model of temporal frequency perception. Vision Res 24:1881-1887.

Marks LE (1979) Summation of vibrotactile intensity: an analog to auditory critical bands? Sensory Proc 3:188-203.

Miller GA (1947) Sensitivity of changes in the intensity of white noise and its relation to masking and loudness. J Acoust Soc Am 19:609619.

Müller J (1948) The specific energies of nerves. In: Readings in the history of psychology (Dennis W, ed). New York: Appleton-CenturyCrofts.

Patterson RD (1974) Auditory filter shape. J Acoust Soc Am 55:802809.

Patterson RD (1976) Auditory filter shapes derived with noise stimuli. J Acoust Soc Am 59:640-654.

Richards VM (1992) The detectability of a tone added to narrow bands of equal-energy noise. 91:3424-3435. 
Rushton WAH (1972) Pigments and signals in colour vision. J Physiol (Lond) 220:1-31P.

Scharf B (1970) Critical hands. In: Foundations of modern auditory theory, Vol 1 (Tobias J, ed). New York: Academic.

Shapley R, Lennie P (1985) Spatial frequency analysis in the visual system. Annu Rev Neurosci 8:547 583.

Talbot WH, Darian-smith I, Kornhuber HH, Mountcastle VB (1968) The sense of flutter-vibration: comparison of the human capacity with response patterns of mechanoreceptive afferents from the monkey hand. J Neurophysiol 31:301-334.

Van Doren CL (1990) The effects of a surround on vibrotactile thresholds: evidence for spatial and temporal independence in the nonPacinian I (NPI) channel. J Acoust Soc Am 87:2655-2661.

Verrillo RT (1962) Investigation of some parameters of the cutaneous threshold for vibration. J Acoust Soc Am 34:1768-1773.

Verrillo RT (1963) Effect of contactor area on the vibrotactile threshold. J Acoust Soc Am 35:1962-1966.

Verrillo RT (1971) Vibrotactile thresholds measured at the finger. Percept Psychophys 9:329-330.
Verrillo RT, Gescheider GA (1975) Enhancement and summation in the perception of two successive vibrotactile stimuli. Percept Psychophys $18: 128-136$.

Verrillo RT, Gescheider GA (1977) Effect of prior stimulation on vibrotactile thresholds. Sensory Proc 1:292-300.

Watson $\Lambda$ B, Pelli DG (1983) QUEST: a Bayesian adaptive psycho metric method. Percept Psychophys 33:113-120.

Watson AB, Robson JG (1981) Discrimination at threshold: labelled detectors in human vision. Vision Res 21:1115-1122.

Waugh SJ, Hess RF (1994) Suprathreshold temporal-frequency discrimination in the fovea and the periphery. J Opt Soc Am A 11: 1199-1212.

Wilson HR, Gelb DJ (1984) Modified line-element theory for spatialfrequency and width discrimination. J Opt Soc Am A 1:124-131.

Zwicker E, Flottorp G, Stevens SS (1957) Critical band width in loudness summation. J Acoust Soc Am 29:548-557.

Zwislocki JJ (1965) Analysis of some auditory characteristics. In: Handbook of mathematical psychology, Vol 3, Chap 15 (Luce RD, Bush RR, Galanter E, eds). New York: Wiley. 